\title{
How to Improve Physical Activities among Student in the Pandemic COVID-19 era?
}

\author{
Savitri Galuh Ayu Ratna ${ }^{1 *}$, Supriyati ${ }^{1}$, and Agustiningsih Denny ${ }^{2}$ \\ ${ }^{1}$ Public Health Sciences, Health Behaviour; Environment and Social Medicine Department, Faculty of Medicine; Public Health and \\ Nursing, University of Gadjah Mada, Yogyakarta \\ ${ }^{2}$ Medical Sciences, Physiology Department, Faculty of Medicine; Public Health and Nursing, University of Gadjah Mada, \\ Yogyakarta
}

\begin{abstract}
Physical activity is one form of healthy behavior, an individual's efforts to maintain or improve health conditions. There are broad spectrum of benefit such as physical, mental and social if we do regular physical activity. Although there are many benefits, based on RISKESDAS 2018 , it is stated that $33.5 \%$ of Indonesians lack in physical activity with the most categories at the age of 10-14 and 15-19 years. Physical activity associated with salutogenic concept which described by the Sense of Coherence value. This study aims to find how to improve physical activity of undergraduate students Faculty of Medicine, Public Health and Nursing, University of Gadjah Mada during pandemic. Methods of this study used quantitative approach with cross-sectional design which held online by share google form link to respondents in April-May 2021 during COVID-19 pandemic and involved 360 respondents who were selected by proportion sampling. Instrument used in the study were SOC-13 questionnaire, International Physical Activity Questionnaire short self-administered and Social Environment questionnaire. Statistical test using logistic regression with STATA 14. Result of this study shows that Social Environment and components in Sense Of Coherence affect how a person's motivation in carrying out activities that beneficial to health such as doing regular physical activity. The results are statistically significant (p-value $0.0000<0.05$ ). Conclusion of this study, to increase physical activity for undergraduate students during the COVID-19 pandemic, a good social environment and sense of coherence are needed.
\end{abstract}

Keywords: sense of coherence, social environment, physical activity, adolescents, covid-19

\section{Introduction}

Healthy behavior is an effort made by everyone to maintain or improve their health condition, avoid health problems and achieve a positive image of their body [1]. Healthy behavior includes efforts to reduce exposure to tobacco or smoking behavior, maintain a balanced diet, physical activity, reduce risky sexual behavior, make regular visits to health workers, screening and vaccination [2]. Physical activity is a healthy behavior. Physical activity is the expenditured of energy by skeletal muscles to carry out any movement in the body. Lack of physical activity in the body triggers various problems including death [3]. Doing physical activity regularly, correctly and measurably helps the body achieve a fit condition that provides many benefits. Physical benefits such as reduced risk of degenerative diseases, improve muscle and joint flexibility, boost the immune system, strengthen the heart muscle, control blood sugar levels, blood pressure and lipid profiles. Socioeconomic benefits reduce the cost of treatment and examination because it avoids various diseases and increases productivity. Psychological aspects can increase self-confidence, help control stress and reduce anxiety and depression [4]. Physical activity for at least one hour a day will optimize the health and development of children and adolescents. In addition, by doing regular physical activity, adolescents' performance in learning will increase [5].

Although many provide benefits, in fact teenagers are still lacking in physical activity. The proportion of Indonesian people in doing physical activity is still lacking, $33.5 \%$ of the Indonesian population lacks physical activity. Two categories of productive age who lack physical activity are age 10-14 years as much as $64.4 \%$ and age $15-19$ years at $49.6 \%$. The percentage of less physical activity in Yogyakarta Province is $27.8 \%$ or $5 \%$ lower than the national average of $33.5 \%$. One of the causes of low physical activity in Yogyakarta is the lack of RTHP (Public Green Open Space). Currently, Yogyakarta only has 45 RTHP points or about $18 \%$ of the total area. Yogyakarta is mostly inhabited by immigrants, both tourists and students and overseas students, the lack of RTHP in Yogyakarta causes the

\footnotetext{
* Corresponding author: gaaluhayuu@mail.ugm.ac.id
} 
surrounding community to find it difficult to carry out physical activities, even light physical activities such as leisurely walks or jogging [6]. The lack of physical activity carried out by adolescents, especially students in Yogyakarta, is one of the causes for them to have difficulty during medical tests on work calls. As many as $57 \%$ of University of Gadjah Mada Engineering Undergraduate students failed to pass the medical test during job selection. After being investigated, during college, many students apply unhealthy lifestyles such as lack of physical activity, indiscriminate consumption of food without paying attention to the nutritional value and hygiene, lack of rest and smoking. In addition to students, the impact of other unhealthy lives is also felt by the University of Gadjah Mada academic community, such as decreased work productivity due to illness and death of lecturers and employees at a relatively young age, this causes University Gadjah Mada to declare itself as a Health Promoting University [7].

Health Promoting University (HPU) at Universitas of Gadjah Mada (UGM) was first initiated by the Faculty of Medicine, Public Health and Nursing (FK-KMK) which is has implemented a smoke-free area since 2004. In addition, FK-KMK also provides jogging tracks, cyclist lanes, traffic light food warnings in the canteen, posters related to healthy behavior, to the dissemination of information through various social media to make a real contribution to HPU. Despite being the initiator, an online survey in the context of developing UGM as HPU to 111 respondents at FK-KMK stated that the topic of physical activity was the least remembered topic, only $36 \%$ [8]. FK-KMK UGM students include students who have a series of solid activities. Based on brief information gathering on one of the resource persons, the FK-KMK UGM student with the initials "F", said that FK-KMK students have a busy class schedule from morning to evening, tutorial or practicum lectures sometimes force students to come early and leave late, not to mention various assignments both individually and in groups such as journal reading, paper making, PBL (Problem Based Learning), which makes them stay on campus to look for wi-fi or find literature in the library until late. The density of these activities makes researchers interested in knowing how they can still get along in a social environment and implement healthy behaviors such as physical activity. Physical activity is also one of the healthy behaviors related to mental health and the salutogenic concept, a concept that seeks to see someone with a healthy paradigm. Mental and psychological health itself is closely related to Sense of Coherence, because it affects how a person's desire and motivation in carrying out an activity [9].

The salutogenic concept focuses on the capacity of the self to stay healthy rather than the classic focus on risk and disease or pathogenesis. In this book, the concept of Sense of Coherence (SOC) is introduced which is defined as a global orientation that: (1) all stimuli faced by humans and the surrounding environment are structured, predictable and controlled, (2) humans have the resources or abilities within themselves to deal with problems. the stimulus, (3) efforts to overcome the stimulus produce something meaningful. This combination of cognitive, behavioral, and motivational aspects forms the concept of SOC. Sense of Coherence consists of three components: Comprehensibility of the perception of the world as something that can be understood and consistent compared to something complicated and unpredictable, Manageability is the ability to maximize the resources you have to deal with a stimulus or stressor and Meaningfulness in the form of emotional expressions that make a sense and desire meaningful [10]. Sense of Coherence has been widely studied in the world of health related to various variable. One of the Sense of Coherence studies state that health promotion can be supported by strengthening the value of Sense of Coherence. Sense of Coherence together with spirituality, social support, Perceived Health and medication can improve the social well-being of individuals in adulthood as important things to facilitate health promotion [11]. In addition to facilitating in terms of health promotion, Sense of Coherence and gender and age have an interaction relationship with physical activity. The stronger the Sense of Coherence, the better the physical activity of a teenagers [12]. Previous research conducted by researchers in 2017 show that the higher the Sense of Coherence value, the higher the level of physical activity of the young woman. Although there is a relationship, the correlation between the two variables is very small, ranging from 0.147 with a significance of 0.012 ( $p$-value $<0.05$ ). The relationship between the two variables also cannot be ascertained as a cause-and-effect relationship because the research method used is cross-sectional. Based on some literature above, it looks like physical activity have been affected by social environment and sense of coherence value. Is it true that sense of coherence and social environment have positive effect in predict improvement of student's physical activity during pandemic COVID-19 era?

\section{Research Methods}

The study was conducted using a quantitative approach with a cross-sectional design. Involving 360 respondents from FK-KMK UGM undergraduate students who were selected according to the inclusion and exclusion criteria with proportion sampling from three study programs: medicine, nursing and nutrition at the second level so that the research sample represents the population. Held around April-May 2021 online with shared google form link to respondent due to the COVID-19 pandemic situation. The research instrument used in this research is the Sense Of Coherence-13 questionnaire and the IPAQ (International Physical Activity Questionnaire) Short Self-Administered which have been translated into Indonesian. While the questionnaire to measure the social environment was developed by the researcher herself. The three instruments were tested for validity and reliability, the results showed that all items were valid and reliable because they had a Cronbach Alpha value $>0.6$. Statistical tests were carried out using logistic regression with the STATA 14 application. The results were significant if the $\mathrm{p}$-value $<0.05$ 


\section{Results}

\subsection{Characteristics of Respondents}

Table 1. Characteristics of Research Respondents.

\begin{tabular}{|c|c|c|}
\hline Characteristic & Category & Total (\%) \\
\hline \multirow[t]{2}{*}{ Gender } & Men & $156(43,33 \%)$ \\
\hline & Women & $204(56,67 \%)$ \\
\hline \multirow[t]{3}{*}{ Age } & $18-19$ Years Old & $110(30,5 \%)$ \\
\hline & $20-21$ Years Old & $167(46,4 \%)$ \\
\hline & $>21$ Years Old & $83(23,1 \%)$ \\
\hline \multirow{5}{*}{$\begin{array}{l}\text { Residency in } \\
\text { Yogyakarta }\end{array}$} & Boarding House & $174(48,2 \%)$ \\
\hline & $\begin{array}{l}\text { Core Family Home } \\
\text { with Mom and Dad }\end{array}$ & $44(12,4 \%)$ \\
\hline & $\begin{array}{l}\text { Relatives of the } \\
\text { Father or Mother }\end{array}$ & $38(10,5 \%)$ \\
\hline & $\begin{array}{l}\text { Student } \\
\text { Accomodation } \\
\text { Center }\end{array}$ & $83(23,1 \%)$ \\
\hline & $\begin{array}{l}\text { Kontrakan Bersama } \\
\text { teman }\end{array}$ & $21(5,8 \%)$ \\
\hline \multirow{5}{*}{$\begin{array}{l}\text { House Rent } \\
\text { with Friends }\end{array}$} & $<1.000 .000$ & $47(13,1 \%)$ \\
\hline & $\begin{array}{l}1.000 .000 \\
2.000 .000 \\
\end{array}$ & $222(61,5 \%)$ \\
\hline & $\begin{array}{ll}2.000 .000 & - \\
3.000 .000 & -\end{array}$ & $46(12,8 \%)$ \\
\hline & $\begin{array}{l}3.000 .000 \\
4.000 .000\end{array}$ & $28(7,9 \%)$ \\
\hline & $>4.000 .000$ & $17(4,7 \%)$ \\
\hline \multirow{4}{*}{$\begin{array}{l}\text { Management } \\
\text { Allowance }\end{array}$} & Diet & $248(69,2 \%)$ \\
\hline & $\begin{array}{l}\text { Sports Club or Gym } \\
\text { Membership }\end{array}$ & $11(2,9 \%)$ \\
\hline & $\begin{array}{l}\text { Books, Medical } \\
\text { Needs, and Other } \\
\text { College Needs }\end{array}$ & $65(18,1 \%)$ \\
\hline & $\begin{array}{l}\text { Secondary and } \\
\text { Tertiary Necesities } \\
\text { such as Shoes, } \\
\text { Clothes, Bags, etc. }\end{array}$ & $36(9,8 \%)$ \\
\hline \multirow{2}{*}{$\begin{array}{l}\text { Perception of } \\
\text { the } \\
\text { Surrounding } \\
\text { Environment }\end{array}$} & $\begin{array}{l}\text { Supporting Healthy } \\
\text { Living Behaviors }\end{array}$ & $304(84,6 \%)$ \\
\hline & $\begin{array}{lr}\text { Less Supportive of } \\
\text { Healthy } \\
\text { Behaviors }\end{array}$ & $56(15,4 \%)$ \\
\hline \multirow[t]{2}{*}{$\begin{array}{l}\text { Perception of } \\
\text { Self - Reliance }\end{array}$} & $\begin{array}{l}\text { Being Able to Carry } \\
\text { Out Healthy Living } \\
\text { Behaviors without } \\
\text { the Influence of the } \\
\text { Surrounding } \\
\text { Environtment }\end{array}$ & (194) $53,8 \%$ \\
\hline & $\begin{array}{l}\text { Implementation of } \\
\text { Healthy Living } \\
\text { Behavior Depends } \\
\text { on the Environment } \\
\text { and People Around }\end{array}$ & (166) $46,2 \%$ \\
\hline
\end{tabular}

\subsection{Results of Research Statistical Analysis}

The results of the initial study stated that gender was a confounding variable, so it was necessary to re- analyze the data by stratifying based on respondent's gender.

Table 2. Results of Male Respondents's Logistic Regression at STATA 14

\begin{tabular}{|c|c|c|c|c|}
\hline $\begin{array}{c}\text { p- } \\
\text { value }\end{array}$ & $\boldsymbol{\beta}$ SOC & $\boldsymbol{\beta}$ SE & $\begin{array}{c}\boldsymbol{\beta} \text { cut } \\
\text { point 1 }\end{array}$ & $\begin{array}{c}\boldsymbol{\beta} \text { cut } \\
\text { point 2 }\end{array}$ \\
\hline 0.0000 & 2.3434 & 4.0559 & 13.4726 & 16.2973 \\
\hline
\end{tabular}

Sense of Coherence and Social Environment variables statistically significantly affect the level of physical activity of male undergraduate students of FK-KMK UGM ( $p$-value was found to be $0.0000<0.05$ ). For the Sense of Coherence variable, every 1 category increase will result in a 2.3-fold increase in the log odds of Physical Activity. In the Social Environment variable, every increase in 1 category will result in a 4.0 -fold increase in the log odds of Physical Activity provided that all other variables in the model are constant. The result of the logistic regression equations are:

(a) Low Physical Activity vs Moderate and high Physical Activity

$\operatorname{logit}(\mathrm{AF})=13.4726+2.3434(\mathrm{SOC})+4.0559$ (ling_sos)

(b) Low and moderate Physical Activity vs High Physical Activity

$\operatorname{logit}(\mathrm{AF})=16.2973+2.3434(\mathrm{SOC})+4.0559$ (ling_sos)

Table. 3. Results of Female Respondents's Logistic Regression at STATA 14

\begin{tabular}{|l|l|l|l|l|}
\hline $\begin{array}{l}\text { p- } \\
\text { value }\end{array}$ & $\boldsymbol{\beta}$ SOC & $\boldsymbol{\beta}$ SE & $\begin{array}{l}\boldsymbol{\beta} \text { cut } \\
\text { point 1 }\end{array}$ & $\begin{array}{l}\boldsymbol{\beta} \text { cut } \\
\text { point 2 }\end{array}$ \\
\hline 0.0000 & 2.3039 & 2.8844 & 9.8028 & 12.1528 \\
\hline
\end{tabular}

Same result for female undergraduate student FK-KMK UGM (p-value was found at $0.0000<0.05$ ). For Sense of Coherence variables, each increment of 1 category will result in a 2.3-fold increase in Physical Activity log odds whereas in a Social Environment variable, each increment of 1 category will result in a 2.9 -fold increase in physical activity odds logs provided that all other variables in the model are constant. The resulting logistic regression equation:

(a) Low Physical Activity vs Medium and High Physical Activity

$\operatorname{logit}(\mathrm{AF})=9.8028+2.3039(\mathrm{SOC})+2.8844$ (ling_sos)

(b) Low and moderate Physical Activity vs High Physical Activity

$\operatorname{logit}(\mathrm{AF})=12.1528+2.3039(\mathrm{SOC})+2.8844$ (ling_sos)

Based on the STATA output results, the probability of male undergraduate students having high physical activity was found to be 10.4 times higher in students with good SOC scores and 57.7 times more in students in good social environments. While the chances of female female students who have high physical activity are found to be 10 times more in female students who have good SOC scores and 17.9 times more in female 
students who are in a good social environment. This applies if the other variables are held constant.

\section{Discussions}

More than half, or as many as 249 , of the total number of respondents in this study had a moderate Sense of Coherence score. The average value of Sense of Coherence in adolescent children is in the range of 57-61 from a maximum value of 91. At adolescence the SOC value is generally around the median because this value can still change over time. The SOC value can increase and decrease depending on the environmental conditions around the teenager [13]. In adolescents, the SOC value is around the median value because there are many things that trigger stressful situations without any resolution so that it affects their mental and physical well-being. Coping mechanisms are more difficult to achieve in adolescence because of various other influencing factors such as behavioral problems, emotional consequences due to socio-economic problems and personal problems such as family difficulties or in relationships with friends [14].

The results of this study stated that more than $80 \%$ of respondents felt that their social environment was quite good and supported in healthy living behavior. Adolescence is considered the most appropriate learning period to understand the social environment. Adolescents learn to understand emotions, intentions, beliefs or beliefs not only for themselves but also for others. For most adolescents, peers become an important social environment in influencing their self-concept, well-being and determination of healthy life behavior [15]. 195 of 360 respondents in this study had a high level of physical activity. Physical activity in adolescents is more active than other age categories. Teenagers do a lot of physical activity because it can avoid various problems that trigger their mental health such as depression, anxiety, anger and stress. Physical activity helps adolescents improve self-esteem and selfconcept [16]. The average teenager has moderate to high physical activity. Body condition that is still prime causes teenagers to be more active and energetic compared to other age categories. Adolescents who routinely engage in physical activity from a young age have a better health-related quality of life compared to adolescents who adopt sedentary behavior [17].

Social Environment and Sense Of Coherence are statistically significant in influencing the level of Physical Activity in both male and female undergraduate students of FK-KMK UGM (p-value $0.000<0.05$ ). A high Sense of Coherence integrates students' abilities for coping and emotional management better so as to create a conducive and supportive social environment not only for the learning process but also for promoting healthy living behaviors such as doing physical activity and regular health checks [18]. The social environment along with the three components of Sense Of Coherence: Comprehensibility, Manageability and Meaningfulness affect individual's physical activity. Comprehensibility is a point of view that believes that everything that happens in this world is predictable and can be controlled. Manageability is the ability to solve problems or stressors in life. Meaningfulness is the desire or motivation to do something. When the individual's social environment is good, the three components in SOC also develop well and further increase the motivational aspect to do positive and beneficial things for the body such as doing regular physical activity [19].

\section{Conclusions}

To increase physical activity for S1-FK-KMK UGM students during the COVID-19 pandemic, a good social environment and sense of coherence are needed. The results of this study shows that Sense of Coherence and Social Environment have positive effect in predict improvement student's physical activity and it is statistically significant. Empower the student to make their own good social environment regularly such as utilization of social media to do home exercise if they can't afford sports club or gym help not only improve their physical activity and health status during pandemic era but also their self-esteem and sense of coherence value.

\section{References}

1. Cockerham, W. C. (2014) Health Behavior, The Wiley Blackwell Encyclopedia of Health, Illness, Behavior, and Society, First Edition.

2. Conner, M. and Norman, P. (2017) 'Health behaviour: Current issues and challenges', Psychology and Health. Routledge, 32(8), pp. 895-906. doi: 10.1080/08870446.2017.1336240.

3. WHO. 2011. Global Recommendations on Physical Activity for Health (18-64 years old). WHO: Geneva.

4. Kementerian Kesehatan, P. D. dan I. (2015) 'Infodatin_Olahraga.Pdf', p. 8.

5. McMahon, E. M. et al. (2017) 'Physical activity in European adolescents and associations with anxiety, depression and well-being', European Child and Adolescent Psychiatry. Springer Berlin Heidelberg, 26(1), pp. 111-122. doi: 10.1007/s00787-016-0875-9.

6. RISKESDAS. 2018. Riset Kesehatan Dasar. Jakarta: Badan Penelitian dan Pengembangan Kesehatan Depkes RI

7. Fathurrohman, Ahmad. 2014. Kegagalan Mahasiswa KMT FT UGM dalam Tes Kesehatan. Yogyakarta: KMT FT UGM

8. Dewi, FST. 2018. Pengembangan UGM sebagai Health Promoting University.

9. Kickbusch, I. (2016) Foreword, The Handbook of Salutogenesis. doi: 10.1007/978-3-319-04600-6.

10. Antonovsky, Aron.1987. Unraveling the mystery of health How people manage stress and stay well. San Fransisco, CA: Jossey-Bass 
11. Von Humboldt, S., Leal, I. and Pimenta, F. (2015) 'Sense of coherence, sociodemographic, lifestyle, and health-related factors in older adults' subjective well-being', International Journal of Gerontology, 9(1), pp. 15-19. doi: 10.1016/j.ijge.2014.01.007.

12. Bronikowski, Laudanska-Krzeminska, Tomaczak \& Marina. 2016. Sense of Coherence, physical activity and ist associations with genderand age among Kosovar adolescent: a cross-sectional study. J Sport Med Phys Fitness.

13. Carlén K, Suominen S, Lindmark U, Saarinen MM, Aromaa M, Rautava P, Sillanpää M. Sense of coherence predicts adolescent mental health. J Affect Disord. 2020 Sep 1;274:1206-1210. doi: 10.1016/j.jad.2020.04.023. Epub 2020 May 11. PMID: 32663952.

14. Oliva MIG, Cunha IPD, Silva AND, Miallhe FL, Cortellazzi KL, Meneghim MC, Coelho TC, Lacerda VR. Sense of coherence and factors associated with school performance of adolescents. Cien Saude Colet. 2019 Aug 5;24(8):3057-3066. Portuguese, English. doi: 10.1590/141381232018248.22642017. PMID: 31389552.

15. Figueiredo CS, Sandre PC, Portugal LCL, Mázalade-Oliveira T, da Silva Chagas L, Raony İ, Ferreira ES, Giestal-de-Araujo E, Dos Santos AA, Bomfim PO. COVID-19 pandemic impact on children and adolescents' mental health:

Biological, environmental, and social factors. Prog Neuropsychopharmacol Biol Psychiatry. 2021 Mar 2;106:110171. doi: 10.1016/j.pnpbp.2020.110171. Epub 2020 Nov 11. PMID: 33186638; PMCID: PMC7657035.

16. Liu M, Wu L \& Ming Q. How Does Physical Activity Intervention Improve Self-Esteem and Self-Concept in Children and Adolescents? Evidence from a Meta-Analysis. PLoS One. 2015 Aug 4;10(8):e0134804. doi: 10.1371/journal.pone.0134804. PMID: 26241879; PMCID: PMC4524727.

17. Wu XY, Han LH, Zhang JH, Luo S, Hu JW, Sun $\mathrm{K}$. The influence of physical activity, sedentary behavior on health-related quality of life among the general population of children and adolescents: A systematic review. PLoS One. 2017 Nov 9;12(11):e0187668. doi: 10.1371/journal.pone.0187668. PMID: 29121640; PMCID: PMC5679623.

18. Chu, J., Khan, M., Jahn, H. and Kraemer, A., 2016. Sense of coherence and associated factors among university students in China: crosssectional evidence. BMC Public Health, 16(1).

19. Mato, M., \& Tsukasaki, K. (2019). Factors promoting sense of coherence among university students in urban areas of Japan: individual-level social capital, self-efficacy, and mental health. Global health promotion, 26(1), 60-68. https://doi.org/10.1177/1757975917691925 